\title{
FINANÇAS: UMA RESENHA DE QUATRO LIVROS
}

Sérgio Ribeiro da Costa Werlang*

A teoria das decisões financeiras, ou teoria das finanças, ou simplesmente finanças, é de longa data objeto de estudo de renomados economistas, dentre eles Kenneth Arrow. A premiação do Nobel de 1990, dado a três economistas por seus trabalhos na área de finanças, Harry Markowitz, Merton Miller e William Sharpe, marcou o reconhecimento definitivo de finanças como campo da ciência econômica.

No Brasil, a área de finanças é normalmente vista como parte do curso de administração e não é ensinada regularmente nos cursos de pós-graduação em economia, uma exceção é a EPGE/FGV, que mantém desde 1980 um campo específico de economia em finanças. Ocorre que há muito a teoria das finanças deixou de ser a matemática financeira.

Diversos resultados importantes de teoria econômica têm sido obtido por finanças. O mais interessante é o fato de poder ser atingida a eficiência de Pareto com o funcionamento de poucos mercados, desde que existam suficientes mercados financeiros e que estes tenham negociações freqüentes (Arrow 1964 e Duffie e Huang 1985). Outro problema importante de inspiração financeira, e ainda sem solução, é o "Paradoxo do Prêmio das Ações" Shiller (1981). Este é o resultado aparentemente paradoxal de que o mercado de ações no longo prazo rende em termos reais muito mais que os títulos de renda fixa. Mesmo levando-se em consideração que os ativos arriscados tenham, em equilíbrio, que render mais que ativos sem risco, ainda assim não há teoria que explique satisfatoriamente a enorme diferença entre os retornos que é verificada empiricamente.

Tendo em vista estes aspectos, fica claro que é importante que a teoria das finanças seja objeto de maior investigação em nosso país. Dentre a imensa quantidade de obras no assunto, foram escolhidas quatro, que se baseiam quase que exclusivamente na teoria de finanças com simetria de informações. Serão abordadas: (1) Foundations for

*Professor da EPGE/FGV

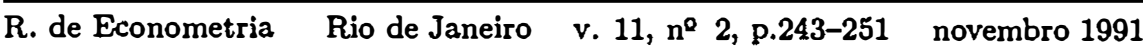


Financial Economics de Chi-fu Huang e Robert Litzenberger, editora North-Holland, 1988; (2) Prices in Financial Markets de Michael Dothan, editora Oxford University Press, 1990; (3) Futures Markets de Darrel Duffie, editora Prentice-Hall, 1989; e (4) Options, Futures and Other Derivative Securities de John Hull, editora Prentice-Hall (há uma "International Edition", de capa mole), 1989.

Dentre os livros que serão resenhados nota-se uma clara ausência de um texto de finanças corporativas ou finanças empresariais (ver Copeland e Weston 1988 e Brealey e Myers 1988), e um texto específico de teoria de preços de ativos sob informação assimétrica (ver Grossman 1989 e Ohlson 1987). A escolha dos livros acima não significa que estes tópicos devam deixar de ser mencionados. Reflete apenas os textos com os quais o autor tem maior familiaridade.

\section{Foundations for financial economics de Huang e Litzen- berger.}

Dos livros que serão resenhados, este é o que mais se preocupa com a inter-relação entre finanças e teoria econômica. Divide-se em 10 capítulos. O primeiro e segundo capítulos cuidam da teoria da escolha envolvendo risco e da dominância estocástica. Essencialmente o material é padrão, podendo ser utilizado em cursos de microeconomia. Estes capítulos são pré-requisitos para qualquer curso na área de finanças. Os capítulos $3,4,6,7$ e 8 cuidam da teoria de determinação de preços de ativos com informação simétrica, isto é, quando os indivíduos concordam com a distribuição de probabilidades que um determinado ativo financeiro segue. É claro que esta hipótese é -restritiva, mas vários importantes resultados podem ser conseguidos.

O terceiro capítulo cuida do modelo de média e variância, isto é, do caso em que as preferências do consumidor são simplesmente representadas por gostar de maior retorno esperado e de menor risco, este último medido pela variância do retorno. É impressionante o quanto esta hipótese consegue atingir em termos de resultados. Os modelos usuais de diversificação de carteira, que são empregados pelos fundos de pensão de todo o mundo, baseiam-se no modelo deste capítulo. Consiste fundamentalmente no trabalho de Markowitz (1952).

O quarto capítulo cuida dos primeiros modelos estáticos de equilíbrio geral com ativos financeiros. Dois são os tópicos abordados: (1) o CAPM ("Capital Asset Pricing Model" - Modelo de Preços 
de Ativos Financeiros), desenvolvido por (Sharpe 1964, Lintner 1965, 1969, Mossin 1966 e Black 1972); e (2) o APT ("Arbitrage Pricing Theory" - Teoria de Preços por Arbitragem), desenvolvido por Ross (1976), como uma possível alternativa ao CAMP. Estes dois modelos são de larga aplicação prática. O CAPM é usado, entre outros, para a avaliação do rendimento dos administradores de fundos de pensão, uso este que deveria ser obrigatório no Brasil. O APT é utilizado para avaliação de ações e outros ativos.

O quinto capítulo é extremamente importante. Nele, os autores entram na teoria de equilíbrio de preços de ativos na generalidade do modelo de Arrow-Debreu, admitindo assimetria de informação e mercados incompletos. Diversas idéias são introduzidas ao longo do texto. Dentre estas a de que, com expectativas racionais, pode-se reduzir em muito o número de mercados necessários para que todas as cestas de consumo estejam disponíveis para os indivíduos Arrow (1964). Várias conclusões de extrema relevância podem ser obtidas, como por exemplo, a ineficiência de Pareto do equilíbrio competitivo quando não há ativos financeiros em número suficiente. É neste capítulo que se vê a importância de instrumentos financeiros sofisticados, como por exemplo, as opçōes: eles têm como função completar mercados Ross (1976a). Por fim, vê-se também a fórmula fundamental de preços ativos: o preço de uma ação hoje é o valor esperado do fiuxo de dividendos futuros, descontado pela taxa marginal de substituição entre o consumo amanhã e hoje. Esta fórmula é a base de muitos estudos empíricos, e tem sido objeto de muita investigação recente, especialmente por conta do Paradoxo do Prêmio das Ações. Este capítulo pode ser utilizado como parte de um curso de microeconomia. O sexto capítulo é uma coletânea de resultados que foram obtidos na literatura com formas específicas para as preferências dos consumidores. É bom que seja seguido, especialmente porque fornece diversas formas empiricamente testáveis. O capítulo sete é a extensão do quinto capítulo para vários períodos. Para que os resultados sejam manejáveis, os autores acabam restringindo-se ao caso de informação simétrica.

O oitavo capítulo é um primor. Cuida da teoria geral de determinação de preços de ativos através da nâo-existência de arbitragens. Diz-se que existe uma oportunidade de arbitragem se através da compra e venda de diversos ativos pode-se conseguir uma quantia 
positiva iniciando-se as operações sem dinheiro. Em outras palavras: uma oportunidade de arbitragem é a possibilidade de produzir lucro do nada. Harrison e Kreps (1979) desenvolveram uma técnica geral de colocar preços em ativos pela não-existência de oportunidades de arbitragem. Esta técnica tem tido amplo uso na determinação do preço de ativos complexos. Basicamente, consiste em achar uma distribuição de probabilidades que tem a propriedade que qualquer ativo financeiro tem seu preço dado pela esperança matemática do valor presente do fluxo de dividendos futuros, esperança esta que é calculada com base nesta probabilidade. Esta distribuição de probabilidades é conhecida como medida martingal equivalente. A apresentação do capítulo é simples e leva o leitor a compreender conceitos que são normalmente apresentados em textos avançados de teorias das probabilidades.

O nono capítulo trata da assimetria de informações. Neste podem ser vistos os modelos que permitem que se discuta a ação do "insider", ou a política de dividendos de uma firma, que pelo teorema de Modigliani e Miller (1958) deveria ser irrelevante. Só que todos sabemos que não o é. É um capítulo muito introdutório, mas que trata o tema de forma unificada e moderna. Pode ser dado como complemento a um curso de microeconomia onde seja tratada a assimetria de informação.

Por fim, o décimo cápitulo é uma excelente fonte de consulta para testes empíricos do CAPM. Note que no Brasil ainda não foram feitos testes completos sobre a validade do CAPM (ou do APT).

Em resumo, a obra em questão não é um texto mais apropriado para um curso de mestrado "latu-sensu", ou de um MBA executivo, mas é o texto mais indicado para que um aluno de economia aprenda as diversas facetas da moderna teoria das finanças e por que motivo é tão importante que ela seja estudada como parte da teoria econômica.

\section{Prices in financial markets de Dothan.}

Este livro é um complemento para o curso introdutório baseado no Foundations For Financial Economics de Huang e Litzenberger (de agora em diante HL, por simplicidade). É integralmente fundamentado na teoria de preços de ativos sob informação simétrica. $\mathrm{O}$ autor parte do pressuposto (correto) de que o mais importante resultado da teoria de preços de ativos sob informação simétrica é a existência 
das medidas martingais equivalentes, abordadas no capítulo oito de HL. Consiste em doze capítulos.

O ponto de partida é o modelo de um período, discutido em detalhe no capítulo dois. O capítulo um introduz a notação e os resultados básicos. Os capítulos terceiro e quarto cuidam do modelo multiperiódico: a existência da medida martingal equivalente num contexto de vários períodos, como no capítulo oito de HL. Até aqui, este livro pode ser encarado como uma revisão do material de HL.

No capítulo quinto Dothan começa a introduzir as técnicas mais avançadas que hoje estão sendo largamente utilizadas na teoria das finanças: a integração estocástica, o teorema de representação de martingais etc. No capítulo ora em análise apresenta-se a teoria na sua forma discreta, para maior familiarização do leitor com o material mais complexo que será introduzido adiante. O capítulo seis cuida ainda de aplicações da teoria discreta.

Os capítulos sete e oito discorrem sobre a base da teoria da negociação contínua: o processo de Wiener, ou movimento Browniano, a integral estocástica de Itô e o lema de Itô. Estas técnicas são aplicadas no nono capítulo ao modelo de Black-Scholes de preços de opções.

Por fim, os capítulos de número dez a doze apresentam o que há de mais avançado em teoria de preços de ativos com simetria de informação: a teoria geral de preços de ativos em economias com negociação contínua.

Este livro é bem mais denso que HL. Podem-se empregar os capítulos um a seis como complemento dos capítulos um a oito de HL em um curso de teoria das finanças sob informação simétrica de um semestre. Contudo, para o pesquisador interessado em trabalhar no campo, é indispensável a leitura dos capítulos mais avançados. Além disso, o livro contém o material que é considerado básico para os "rocket scientists" de Wall Street, de forma que está longe de ser um texto teórico e desvinculado da prática.

\section{Futures markets de Duffie.}

Este livro e o próximo são de um caráter completamente distintos dos dois anteriores. São textos para serem usados em um curso de mercados futuros e de opções que possa ser absorvido por alunos de um MBA executivo. Também têm utilidade para cursos mais práticos de finanças, que podem ser assistidos por alunos de economia, e como 
manual para profissionais de mercado. Futures Markets é composto de nove capítulos.

Os primeiros três capítulos apresentam detalhes históricos, institucionais e operacionais. A diferença entre mercados futuros ("futures") e a termo ("forward") é explicada. Embora a operacionalização dos mercados futuros brasileiros tenha seguido de perto a dos mercados americanos, é importante complementar o conteúdo destes capítulos com informações específicas das características dos contratos negociados nas bolsas brasileiras. A bolsa de futuros que é mais ativa no Brasil de hoje é a BM\&F (Bolsa Mercantil e de Futuros). Basta coletar na $B M \& F$ informações sobre os contratos que têm negociação regular.

O quarto capítulo cuida da teoria de equilíbrio em mercados futuros. É uma versão bem simples das teorias de formação de preços futuros, baseada na análise média-variância. $O$ apêndice cuida de tópicos mais avançados e não deve deixar de ser lido, pois incorpora a teoria da utilidade esperada e a determinação simultânea do preço futuro em diversos mercados. Pode ser acompanhado pela leitura de (Anderson e Danthine 1983 e Danthine 1978).

$\mathrm{O}$ quinto capítulo mostra a determinação do preço futuro e a termo com base na não-existência de arbitragem. A relação fundamental é que se não há custos em estocar o ativo sobre o qual o contrato futuro (ou a termo) é negociado, então o preço futuro tem que ser igual ao preço à vista composto pelos juros do período até ao vencimento do contrato. Em seu apêndice A apresenta a equivalência entre o preço a termo e o preço futuro, sob a hipótese de previsibilidade perfeita da taxa de juros, de acordo com Cox, Ingersoll e Ross (1981). É importante que seja compreendida a diferença entre a arbitragem em mercados a termo e mercados futuros, de modo que o apêndice contém material relevante.

O capítulo seis é estatístico e preparatório para o sétimo. Este analisa em detalhes a utilização de mercados futuros como instrumentos de proteção ("hedging"). De novo, os apêndices são de grande importância prática e teórica. Em particular os apêndices $\mathrm{B}, \mathrm{E}$ e F são muito interessantes.

O oitavo capítulo pode ser considerado como uma introdução à teoria de preços de opções. É um capítulo apenas acessório, que poderia ser deixado de lado desde que se usasse mais tarde um outro 
texto específico de opções, como o que será abordado adiante.

O capítulo nove é extremamente importante, mas apenas toca nos problemas de organização industrial de mercados futuros: como devem ser regulados as bolsas e os mercados futuros? $\mathrm{O}$ apêndice $\mathrm{E}$ lista todas as bolsas de futuros que existiam no mundo, e é bastante completo.

Este livro é muito básico, mas mostra uma visão uniforme da teoria e da prática nos mercados futuros. Além disso, a bibliografia é excelente, podendo ser empregada para a complementação do material dos capítulos.

\section{Options, futures, and other derivative securities de Hull.}

Este livro surgiu para desbancar a "bíblia" da teoria de opções, Cox e Rubinstein (1985). O texto de Cox e Rubinstein continua sendo uma referência, mas sofreu pelo pioneirismo. Houve muitas inovações desde a sua publicação. O livro de Hull é o que melhor apresenta as complexidades dos mercados de opções. Divide-se em treze capítulos, muitos dos quais com apêndices. Diferentemente do texto de Duffie, os apêndices trazem assuntos avançados, de modo que podem ser suprimidos em uma primeira leitura.

O primeiro capítulo é uma introdução aos diversos ativos e estratégias disponíveis. $\mathrm{O}$ capítulo seguinte contém uma discussão detalhada da diferença entre mercado a termo e mercado futuro, na linha do capítulo cinco do livro de Duffie, que foi visto anteriormente. a vantagem é que o texto de Hull apresenta vários casos particulares detalhadamente.

O terceiro e o quarto capítulos apresentam o modelo de BlackScholes. Isto é feito de forma acessível ao leitor com conhecimento de cálculo de várias variáveis. Adicionalmente, Hull introduz ao leitor a técnica de cálculo do preço de ativos com neutralidade ao risco ("risk neutral pricing" - o valor de um ativo é dado pelo seu valor presente esperado). Esta é uma versão simplificada da utilização da medida martingal equivalente.

$\mathrm{O}$ quinto capítulo descreve pormenorizadamente as relações e o preço de opções de compra e venda sobre ações. Mostra a complexidade do problema quando as opções são americanas, ou seja, quando podem ser exercidas até a data do vencimento. 
O sexto e sétimo capítulos são muito importantes. Contêm material avançado sobre opções e ativos que não podem ser avaliados de imediato pela fórmula de Black-Scholes, assim como um arcabouço teórico geral para o cálculo do preço de ativos.

O capítulo oito mostra como utilizar os modelos de preço que foram estudados até então. É fundamental para os leitores que tenham objetivos práticos. Merece especial destaque a excelente exposição do seguro de carteira ("portfolio insurance"), técnica que é de amplo uso em administração de carteiras.

O capítulo nono é o companheiro de qualquer financista aplicado. Como foi visto nos capítulos anteriores, os preços dos ativos seguem, muitas vezes, equações diferenciais parciais que não têm solução fechada. Desta forma, faz-se necessária uma incursão nos métodos numéricos. É interessante observar que é neste ponto que se distingue um bom de um mau modelo. Nem sempre o mais preciso é o melhor, pois o tempo decorrido entre o início e o fim de um cálculo é, muitas vezes, o determinante da execução de uma arbitragem bem sucedida.

Os capítulos dez e onze trazem uma boa abordagem de ativos financeiros que são baseados em taxas de juros, e de seus correlatos, os "swaps". O capítulo doze trata de fórmulas distintas para o cálculo do preço de opções. Por fim, o décimo terceiro encerra o livro, com uma revisão dos conceitos fundamentais.

\section{Referências}

Anderson, R. \& Danthine, J. P. 1983. "Hedger diversity in futures markets." Economic Journal 93:370-389.

Arrow, K. 1964. "The role of securities in the optimal allocation of riskbearing." Review of Economic Studies 31:91-96.

Black, F. 1972. "Capital market equilibrium with restricted borrowing." Journal of Business 45: 444-454.

Brealey, R. \& Myers, S. 1988. Principles of Corporate Finance. $3^{\mathrm{a}}$ edição, Nova Iorque: McGraw-Hill..

Copeland, T. E. \& Weston, J. F. 1988. Financial Theory and Corporate Policy. $3^{a}$ edição Reading. MA: Addison-Wesley.

Cox, J. \& Rubinstein, M. 1985. Options Markets. Englewood Cliffs. NJ: Prentice-Hall. 
Cox, J., Ingersoll J. \& Ross, S. 1981. "The relation between forward prices and futures prices." Journal of Financial Economics 9:321-346.

Danthine, J. P. 1978. "Information, futures prices, and stabilizing speculation." Journal of Economic Theory 17:78-98.

Duffie, D. \& Huang, C. 1985. "Implementing Arrow-Debreu equilibria by continuous trading of few long-lived securities." Econometrica 53: 1337-1356.

Grossman, S. 1989. The Informational Role of Prices. Cambridge. MA: MIT Press.

Harisson, M. \& Kreps, D. 1979. "Martingales and arbitrage in multiperiod securities markets." Journal of Economic Theory 20: $381-408$.

Lintner, J. 1965. "The valuation of risky investments in stock portfolios and capital budgets." Review of Economics and Statistics 47: $13-37$.

Lintner, J. 1969. "The aggregation of investor's diverse judgements and preferences in purely competitive markets." Journal of Financial and Quantitative Analysis 4:346-382.

Markowitz, H. 1952. "Portfolio selection." Journal of Finance 7:77-91. Modigliani, F. \& Miller, M. 1958. "The cost of capital, corporation finance, and the theory of investment." American Economic Review 48: 261-297.

Mossin, J. 1966. "Equilibrium in a capital asset market." Econometrica 35: 768-783.

Ohlson, J. 1987. The Theory of Financial Markets and Information. Nova Iorque: North-Holland.

Ross, S. 1976. "Arbitrage theory of capital asset pricing." Journal of Economic Theory 13:341-360.

1976a. "Options and efficiency." Quarterly Journal of Economics 90: 75-89.

Shiller, R. 1981. "Do stock prices move too much to be justified by subsequent changes in dividends?." American Economic Review 71: 421-436.

Sharpe, W. 1964. "Capital asset prices: a theory of capital market equilibrium under conditions of risk." Journal of Finance 19:425 -442 . 
